\title{
Värvinimed ja värvid vendade Grimmide muinasjutu "Lumivalguke" variantides
}

\begin{abstract}
Urmas Sutrop
Teesid: Artiklis käsitletakse vendade Grimmide "Lumivalgukese" muinasjutu kolme varianti ning uuritakse neis esinevate värvide ja värvinimede tähendusi ning nii nimede kui ka tähenduste muutumist. Analüüsil lähtutakse muinasjuttude uurimise strukturaalsest meetodist ning uuritakse värvide ja nende nimede sümboolseid tähenduste opositsioone nagu sees ja väljas, valgus ja pimedus, elu ja surm, loogiline ja mütoloogiline. Analüüsil toetutakse ka põhivärvinimede teooriast lähtuvale eristusele, mille kohaselt must, valge ja punane on kõige fundamentaalsemad värvinimed. Samas on värvinimede kasutamine (semantika ja sümbolism) "Lumivalgukese" variantides komplitseeritud, kuna värvil võib korraga olla mitu vastandlikku tähendust. Tegemist ei ole ainult lihtsate binaarsete opositsioonidega. Vennad Grimmid pidasid värve must, valge ja punane ilusateks värvideks. Jacob Grimm kirjeldas neid kui poeesia kolme värvi.

Märksõnad: Lumivalguke, opositsioonid, põhivärvinimed, strukturalism, vennad Grimmid
\end{abstract}

Vennad Grimmid redigeerisid oma eluajal korduvalt enda kogutud ja avaldatud muinasjutte. Selle põhjuseks oli nii lastevanemate, kooliõpetajate kui ka kirikuesindajate kriitika nende muinasjutuväljaannete ja seal leiduva brutaalsuse kohta. Grimmide esimene käsikirjaline muinasjutuvalik aastast 1810, mis sisaldas 48 teksti, ei jõudnud trükki. Grimmide esimene Laste ja kodu muinasjuttude suur väljaanne ilmus 1812 . aastal ning nende viimane, 1854. aastal redigeeritud seitsmes väljaanne ilmus 1857. aastal. Grimmide eluajal ilmus ka kümme muinasjuttude väikest väljaannet.

Päris esimese "Lumivalgukese" muinasjutu variandi oli Jacob Grimm üles tähendanud juba varem. 1808. aasta aprillis saatis ta selle oma õpetajale Friedrich Carl von Savignyle (Rölleke 2013: 216). Muinasjutt oleks võinud saada ka alapealkirja "Õnnetu laps", mille Jacob Grimm kirjutas hiljem 1808. aasta käsikirjale. ${ }^{1}$ 
Kuna Grimmid redigeerisid põhjalikult oma muinasjutte, otsustasin vaadata, kas ja kuidas on muudetud värvinimesid. See heidab ka valgust sellele, mismoodi vennad Grimmid oma muinasjutte redigeerisid. Teisalt peetakse "Lumivalgukese" muinasjutu kõige tuntumaks motiiviks just kangelanna kujutluspildi seotust värvidega: "valge nagu lumi, punane nagu veri ja must nagu eebenipuu" (Shojaei Kawan 2005-2006: 241). Ka see õigustab valitud teemat. Seetõttu keskendungi käesolevas artiklis ainult "Lumivalgukese" muinasjutule ja jätan teised muinasjutud kõrvale. Põhjuseks on see, et "Lumivalgukese" muinasjutt seostub kõigile kolme värviga - valge, punane ja must.

Värvide teemaga Grimmide "Lumivalgukese" muinasjutus on tegelnud Vaz da Silva (2007), Angelopoulos (2008) ja Rölleke (2013). Eesti autoritest on Kärri Toomeos-Orglaan näidanud, et värvidel on muinasjuttudes küllaltki oluline roll ja positsioon $(2016){ }^{2}$

Muinasjuttude uurimises võib väga jämedalt eristada kahte traditsiooni. Lihtsustatult võtab ajaloolis-geograafiline traditsioon arvesse ühe muinasjutu kõik variandid kõikidest maadest, kus see esineb, olenemata muinasjutu jutustamise ajast. Strukturaalse lähenemise puhul analüüsitakse ühte konkreetset lugu.

Käesolevas artiklis kasutan strukturaalset lähenemist ning analüüsin vendade Grimmide "Lumivalgukese" kolme varianti ning jätan kõrvale kõik teised Lumivalgukese motiividega muinasjutud ja variandid.

\section{Allikad (materjal) ja meetod}

Vaatluse alla tulevad "Lumivalgukese" muinasjutu (ATU 709) kolm varianti: 1810. aasta käsikirjaline algvariant, mille Grimmid saatsid Clemens Brentanole, esimene trükitud variant aastast 1812 ning viimane Grimmide redigeeritud variant (7. trükk) aastast 1857.

Kõik vendade Grimmide Laste ja kodu muinasjuttude suure väljaande seitse trükki on digitaalselt nii teksti kui ka pildina kättesaadavad Wikisource’i lehel "Kinder- und Hausmärchen" (Brüder Grimm 1812-1857a) või veel lihtsamalt Wikisource'i lehel "Schnewittchen" (Brüder Grimm 1812-1857b). "Lumivalgukese" muinasjutt on kõikides suurtes väljaannetes järjekorras 53. (KHM 53). "Lumivalgukese" muinasjutu 1810. aasta algvariant on võetud Kurt Derungsi toimetatud väljaandest (Brüder Grimm 2010). Eestikeelsed tõlkevasted pärinevad väljaandest Lumivalgukeste raamatuke (Sutrop 2016). ${ }^{3}$

Kasutan nime Lumivalguke alamsaksakeelse Schneewittchen (Sneewittchen) vastena ja nime Lumivalgeke ülemsaksakeelse Schneeweißchen vastena. 
Grimmid ise eelistasid enamasti alamsaksakeelset nimekuju, kuigi 1810. aasta algkäsikirjas oli ülemsaksakeelne nimekuju.

Värvinimesid käsitlen lähtuvalt põhivärvinimede teooriast (vt Berlin \& Key 1969; Uusküla \& Sutrop 2011). Põhivärvinimede teooria eristab igas keeles põhivärvinimed ja mittepõhivärvinimed. Siin ei hakka ma põhivärvinime defineerima. Põhivärvinimesid on maksimaalset üksteist, mõnes keeles ka kaksteist. Kogu värvimaailma rikkus antakse kõikides keeltes edasi mittepõhinimedega. Teooria ütleb, et igas keeles on vähemalt kaks põhivärvinime - must ja valge. Kui keelde ilmub kolmas põhivärvinimi, siis on see punase jaoks. Seega on must, valge ja punane kõige vanemad ja fundamentaalsemad põhivärvinimed ning vastavad värvikategooriad inimkeeles kõige primitiivsemad.

Põhivärvinimede teooria tegeleb liialt psühholingvistiliste küsimustega ning jätab kõrvale värvinimede kasutusega seotud küsimused. Sellekohast kriitikat ja lahendusi, kuidas opositsioonide (keeletelgede) abil organiseerida keelelist värviruumi, olen käsitlenud artiklis "Towards a semiotic theory of basic colour terms and the semiotics of Juri Lotman" (Sutrop 2011). Käesolevas artiklis vaatlen eelkõige põhivärvinimede kasutamist värvikeeles ja poeetilises tekstis (muinasjuttudes). Seejuures lähtun värvinimede puhul sellistest opositsioonidest (keeletelgedest) nagu sees ja väljas, valgus ja pimedus, elu ja surm, loogiline ja mütoloogiline, hea ja halb.

\section{Värvinimed ja värvid "Lumivalgukese” muinasjutus}

Vendade Grimmide muinasjutus "Lumivalguke” ei ole kuigi palju värvinimesid. Ometi seostub muinasjutt just kolme põhivärvinimega valge, punane ja must, mis muinasjutus väljendavad ema soovi ning on omistatud peategelasele Lumivalgukesele. Samal ajal on need põhivärvinimed omistatud ka objektidele, mis on tüüpiliselt seda värvi - valge kui lumi, punane kui veri ja must kui eebenipuu. Nii nagu kangelanna omadused on seotud nende kolme põhivärvinime ja neile nimedele iseloomulike objektidega, põhineb ka kangelanna nimi Lumivalguke põhinimel valge ja sellele iseloomulikul objektil lumi. Muinasjutu kangelanna on valge nagu lumi ja teda kutsutakse hellitavalt Lumivalgukeseks. ${ }^{4}$

Opositsioon põhivärvinimede valge, musta ja punase kasutamise ning ülejäänud põhivärvinimede (kollane, roheline, sinine) või siis sekundaarsete värvinimede (kuldne) kasutamise või hoopis värvinimede puudumise vahel on seotud eelkõige Lumivalgukese ja tema ema või siis loo hilisemates versioonides, alates teisest trükist, võõrasema - kauni kuninganna vastandusega. ${ }^{5}$

Kõik kolm vaatlusalust "Lumivalgukese" varianti algavad kirjeldusega, mis vastandub ülejäänud muinasjutule, mis annab kõigele raami. Kuningan- 
na istub akna juures ja õmbleb. Aknaraamid on mustast eebenipuust, väljas sajab lund. Ilma ütlematagi on selge, et lumi on väljas valge, sest last soovides mõtles kuninganna, et oleks laps valge nagu lumi. Siin on opositsioon pimeda toa, mis on raamitud musta eebenipuuga, ja lumivalge välismaailma vahel. Selles pimedas toas sünnivad hiljem tumedad mõtted ja teod, mis tungivad ka puhtasse ja rõõmsasse välismaailma. Muinasjutu teine põhiopositsioon on loo alguse ja lõpu vahel, kus aetakse rauast tuhvlid hõõguma (hõõguv raud on teadupoolest punane!) ja karistuseks sunnitakse kuningannat neis tuhvlites seni tantsima, kuni ta surnult maha kukub. ${ }^{6}$ Neis opositsioonides ilmnevad kõik kolm põhivärvi - valge, punane ja must. Kusjuures must osutab tumedatele tegudele lossis, valge välismaailmale ja Lumivalgukese puhtusele ning punane kättemaksule.

Ka Vaz da Silva osutab sellele, et kuninganna näeb valge ja punase kontrasti läbi musta raami (2007: 243) ning seostab musta värvi teispoolsusega seotud rongaga. Ta kirjutab, et must ilmub ainult valge ja punase põhimise kontrasti kõrval ning selle värvi kohta on tal "vähe lisada" (ibid. 246). Samas Shojaei Kawan peab musta aknaraami Grimmide oskuslikuks lisanduseks "Lumivalgukese" muinasjuttudele. Ta kirjutab, et "eebenipuust aknaraam toob esile kuningliku kodu elegantsuse ja viimistluse" ning oletab samuti, et suulises traditsioonis võis musta eebenipuu asemel olla paheline ronk (2005-2006: 244). ${ }^{7}$

Aga valgusega on opositsioonis ka tume mets (1810), kus elavad päkapikud ja mis siiski osutub heaks paigaks, kuhu halb kuri kuninganna peab maskeeritult sisse tungima. Samas on selles episoodis (1812) olemas kolm värvi - valge, must ja punane. Valge esineb Lumivalgukese nimes, punased on roosid ning musta asendab mittepõhivärvinimi tume. Selles stseenis on tume mets samasuguseks raamiks nagu must eebenipuust aknaraam muinasjutu alguses. Tume mets raamib puhta südamega (puhas süda, 1857) Lumivalgukest, keda tahetakse ohverdada (punased roosid) metsloomadele.

Kohe algusest peale vastandub muinasjutus loogiline ja mütoloogiline. Kuninganna istub akna juures ja õmbleb ning vaatab lund. Seejuures torkab ta endale nõelaga sõrme ning kolm tilka verd langeb lumele. Loogilises maailmas oleks raske aru saada, kuidas akna juures istuja veri langeb mustade raamidega aknast välja valgele lumele ja mitte põrandale või kuninganna riietele.

Ja nii soovibki kuninganna, et tal oleks laps - valge nagu lumi, punapõskne nagu veri (1810), hiljem lihtsalt punane kui veri (1812 ja 1857) ning mustasilmne nagu eebenipuust aknaraamid (1810), lihtsalt must (1812) või mustade juustega nagu eebenipuu (1857).

Üheski kolmest Lumivalgukese variandist ei ole osutatud, mis on Lumivalgukese juures valge. See on meie kujutlusvõime, mis paneb arvama, et nt Lumivalgukese nahk võiks olla lumivalge. ${ }^{8}$ Antti Aarne ei räägi "Lumivalgukese" 
muinasjutu tüübikirjelduses üldse värvidest (1910: 32, nr 709). Stith Thompson on aga Aarne tüübikirjeldust täiendades ekslikult lisanud, et Lumivalgukesel on nahk nagu lumi ning huuled nagu veri (Aarne \& Thompson 1961: 245, $\mathrm{nr}$ 709). Kuigi Jones kritiseerib Aarne-Thompsoni "Lumivalgukese" muinasjutu tüübikirjeldust (Jones 1983: 58), ei märka ta seal Thompsoni ekslikku värvide käsitlust ning kordab seda: "naine ... soovib last, kelle huuled oleksid punased nagu veri ja nahk valge nagu lumi" (ibid.: 60). ${ }^{9}$ Kujutlusvõimega on seotud ka G. Ronald Murphy arvamus, kui ta kirjutab valge värvi kohta, et Lumivalgukese ema soovis last, kes on "punane", mille tähenduseks on lapse punased põsed, ning kes on "valge nagu lumi", mis kombinatsioonis teiste värvidega võib osutada tüdruku nahale. Ta lisab, et lugeja kujutlusvõime ei ole siiski täielikult juhatuseta jäetud (2000: 123).

Valge värvi interpretatsioon sõltub ka diskursusest. Mõneski nahavärviga seotud diskursuses peetakse valget viiteks valgele rassile. Psühhoanalüütilistes diskursustes aga süütusele ja puhtusele. Ka punase interpretatsioon sõltub diskursusest. Mitmedki feministlikud ja psühhoanalüütilised tõlgendused seovad punase värvi naiseks olemise, naiseks saamise ja menstruatsiooniga (nt Bettelheim 2007: 135; Girardot 1977: 281-282).

Punane on põskede värv nii algses variandis (1810): "oleks mul ometi laps, nii punapõseline nagu see veri” kui ka hiljem (1812 ja 1857: Lumivalguke nägi välja nii värske ning tal olid ilusad punased põsed, et teda ei saanud maha matta). Algses variandis on punane ka punaste rooside värv metsas, kuhu kuri ema oma tütre maha jättis, lootuses, et metsloomad tüdruku varsti ära söövad (1810). Punane on elu ja surma sümbol. Punane veri on ohverdus nagu kolm tilka verd, punased põsed on nii Lumivalgukesel, kui ka just punaselt poolelt mürgitatud ounal, kus punane peaks osutama surmale, osutab aga ometi elule, sest Lumivalguke ei sure. Jumalakartmatu kuninganna aga, kes sõi õunapoole, mis ei olnud punane, peab muinasjutu lõpus surema. Karistuseks peab ta hõõguvates (1810 ja 1812) või hõõguvpunastes (1857) raudtuhvlites end surnuks tantsima.

Punane on surmaga seotud elu värv ka pihiku nöörimispaelte kirjelduses (1812), kus see oli punutud kollasest, punasest ja sinisest siidist. Hiljem on muinasjutus igat värvi nöörimispaelad, mis olid punutud kirjust siidist (1857). Sinine esinebki ainult ühe korra siidist nöörimispaela kirjelduses (1812). Muinasjutu algses variandis pole paeltel aga üldse värvi. Ka nöörimispaela kasutati Lumivalgukese tapmiseks, mis aga ei õnnestunud.

Kollane on algselt Lumivalgukese juuste värv - vanakeseks maskeerunud kuninganna astus sisse ja hakkas Lumivalgukese kollaseid juukseid kammima (1810). Kollasega on seotud mittepõhivärvinimi kuldne. Päkapikud kirjutasid läbipaistvale klaaskirstule kuldsete tähtedega tüdruku nime ja päritolu. 
Kui Lumivalgukese juuksed olid kollase asemel mustad nagu eebenipuu (1857), siis kollane värv vabanes. Varem oli kuninganna muutunud kadedusest kahvatuks (1812), hiljem aga muutub kadedusest kollaseks ja roheliseks (1857). Kollane oli ka üks siidpaela värve (1812). Kuningannat iseloomustab ka see, et ta värvib oma näo ära (1812 ja 1857), kuigi ei ole öeldud, mis värvi. Kahes variandis jääb saladuseks, mis värvi oli õuna mürgitamata pool (1810 ja 1812). Muinasjutu viimases variandis on õun väljast ilus, valge ja punapõseline. Kuninganna ütleb kaheks osaks lõigatud õuna kohta "punase sööd sina, valge söön mina" (1857). Valge tähistab siinses opositsioonis näiliselt elu, tegelikult surma, sest kuninganna, kes sööb valge mürgitamata ounapoole, sureb muinasjutu lõpus punaselt hõõguma aetud sussidega tantsides, Lumivalguke, kes sööb mürgitatud punase õunapoole, jääb elama ja abiellub ning on kõige ilusam kogu maal (vt ouna kirjeldust ka eespool).

Ühes variandis tähistab valge puhtust ja hoolsust. Kui Lumivalguke jõudis seitsme päkapiku majja, siis olid seal seina ääres "seitse voodikest, mis olid üles tehtud ja lumivalgete linadega kaetud" (1812). See et voodilinad olid lumivalged, osutab ka sellele, et Lumivalguke oli puhas ja hoolas.

Must värv sümboliseerib ühelt poolt kurjust lossis. Teisalt on ta seotud eluga. Loo algses variandis (1810) soovib ema omale mustasilmset tütart. Muinasjutu esimeses trükitud versioonis (1812) on kirjeldus, kuidas Lumivalgeke lamas kaua-kaua kirstus ega lagunenud. Ta oli ikka nii valge nagu lumi ja nii punane nagu veri. "Ja kui ta oleks saanud oma silmad lahti teha, oleksid need olnud nii mustad nagu eebenipuu." Siin osutab must värv sellele, et ka silmad ei olnud veel lagunema hakanud ja silmaterad olid veel mustad nagu magajal. Siin on kõik kolm värvi - valge, punane ja must - elu värvid. Lumivalgukesel olid “ikka veel ilusad punased põsed", ta oli ikka veel nii värske nagu elus inimene (1812 ja 1857). Aga muinasjutu ajaliselt viimases versioonis, kus must ei ole enam silmade, vaid juuste värv, tekib vastandus elu ja surma värvide punase ja musta vahel. Lumivalgukesel on ilusad punased põsed, ta on nii värske nagu elus. "Teda ei saa me küll musta mulla sisse matta." Mustale mullale vastandub omakorda klaasist läbipaistev kirst, millel on kuldsete tähtedega kiri (1857).

Viimases variandis (1857) tulevad Lumivalgukest, kes lamab läbipaistvas kirstus, taga nutma ka loomad: "kõigepealt öökull, siis ronk, ja lõpuks üks tuvike”. Kõik need olendid on osalised punase, musta ja valge värvisümboolikas. Öökulli iseloomustavad punased silmad, ronk on must lind ja tuvike sümboliseerib valget, puhtust ja võib-olla ka armastust.

Kui küsida, miks vennad Grimmid on selles muinasjutus kasutanud kesksena punast, musta ja valget, tuleb vastust otsida nende endi käsitlusest. Lumivalgukese muinasjutu alguses osutatakse, et punane valgel on nii ilus: "seejärel sai ta imekauni tütrekese, nii valge kui lumi, nii punase kui veri, nii musta 
kui eebenipuu" (1810); "kolm tilka verd langes lumele. Ja kuna punane nägi valgel / valgel lumel nii ilus välja ..." (1812 ja 1857).

Jacob Grimm on tegelenud kolme värvi - valge, punase ja mustaga - teadaolevalt juba 1807. aastal seoses Parzivaliga - punane kui veri, must kui pigi (vt Rölleke 2013: 2015). Hiljem on ta punast, musta ja valget seoses lillede tähendusega kirjeldanud kui poeesia kolme värvi (1813: 140).

Jacob Grimm on kolme värvi probleemile muinasjuttudes andnud universalistliku seletuse. Ta toob näiteks Isaac Jacob Schmidti Idamongolite ajaloo väljaande (Schmidt 1829: 139), kus "Elbek Nigülessuktschi Chagan tappis ühel talvepäeval noolega jänese, ning kui ta märkas lumel jänese verd, siis ta hüüatas: "Oleks mul ometi naine, kelle nägu oleks nii valge nagu see lumi, kelle põsed oleksid nii punased nagu see veri!'” Jacob Grimm jätkab, et muidugi on võimalik motiive punase ja valgega juurde leida, "aga kindlasti ei tarvitse need mõttesaladused olla Mongooliast või Iirimaalt sisse toodud Itaaliasse või Saksamaale. Inimestel on need mõtted vahetult rinnapiimaga saadud, nagu ka kõigi rahvaste poeetide kasutatav eepiline väljendus ilu võrdlemisel lume ja verega. Kui sobivalt tuleb selline tunnistus neile, kes tahavad endale aru anda lihtsa muinasjutupoeesia seletamatu, kuid siiski loomuliku leviku kohta" (Grimm 1846: XXIII).

Seega Grimmide järgi leidis värvide poeesia vormi järjest väljaarendatumates "Lumivalgukese" muinasjutu variantides. Ernst Böklen, kes uuris "Lumivalgukese" muinasjutu variante erinevatel rahvastel, märgib samuti, et "Lumivalgukese" muinasjuttudes kirjeldatakse Lumivalgukest ilusate värvidega. Aga just seda peab ta Grimmide "Lumivalgukese" muinasjutu nõrkuseks. Kogu muinasjutu algus, kus kuninganna talvel akna all tikib ning endale nõelaga sõrme torkab nii, et veri lumme tilgub, on Bökleni arvates natuke ebaloomulik (1910: 64). Kuid Grimmide muinasjuttude varased kommenteerijad Johannes Bolte ja Georg Polívka jagasid vendade Grimmide arvamust, et lastetu naise soov saada last, kes oleks valge nagu lumi, punane nagu veri ja must nagu eebenipuu (ka muinasjuttudes "Kadakapuust" (KHM 47) ja ühes "Tuhkatriinu" variandis (KHM 21)), on ilu igivana poeetiline väljendus (1913: 461).

Käsitlusega, et Laste ja kodu muinasjuttude punase-valge-musta kontrast on ilu muistne väljendus, ei nõustu Philip Mellen, kes peab seda pigem ühiskondade sotsiaalseks praktikaks ja võib pigem väljendada kellegi õilsaid (aadellikke) omadusi (Mellen 1991: 192). Sama väidab ka Vaz da Silva, kes kirjutab, et "värvide kasutamisel muinasjuttudes ei ole tegemist tühja abstraktsiooniga, pigem on see osa tajupõhiste kultuuriliste väärtuste üldisest kodeeringust" (2007: 250). Samas jääb ta Grimmidega sarnasele universalistlikule positsioonile, mille kohaselt musta-valge-punase trio "esindab püsivaid semantilisi väärtusi läbi žanrite ja kultuuride". Seejuures tunnistab ta kultuurispetsiifilisi variatsioone ja detailirikkust (samas). 


\section{Kokkuvõtteks}

Vendade Grimmide muinasjutu "Lumivalguke" (ATU 709, KHM 53) kolm varianti ja selle kangelanna - Lumivalguke - on eelkõige seotud kolme põhivärvinimega - must, valge ja punane. Lisaks esinevad muinasjutu variantides põhivärvinimed kollane, roheline ja sinine. Mittepõhivärvinimedest esinevad kuldne ja tume, kahvatu, hõõguv ja hõõguvpunane. Lisaks võib värvinimede hulka arvata sõna kirju ning verbi värvima.

Iseloomulik on ka värvide puudumine või nende valik kuninganna juures. Kuninganna läks kadedusest kahvatuks või muutus näost kollaseks ja roheliseks. Ta värvis oma näo, et end moondada. Kuninganna pidi karistuseks end hõõguvpunastes sussides surnuks tantsima.

Lumivalguke on alguses kollaste juustega, tema põsed on punased ning silma(tera)d mustad. Mustad silmad ja punased põsed tähistavad seda, et laip näeb värske välja ega ole veel lagunema hakanud. Alles hiljem omistatakse must värv Lumivalgukese juustele.

Punane värv iseloomustab Lumivalgukese põski, aga ka mürgitatud õunad on punapõselised. Hõõguvpunased on sussid, milles kuninganna end muinasjutu lõpul peab karistuseks surnuks tantsima. Mis Lumivalgukese juures on valge, see jääb muinasjutus selgusetuks.

Värvide semantika on Lumivalgukese muinasjutus komplitseeritud. Värvidel võib korraga olla mitu vastupidist tähendust. Kui vaadata elu ja surma vastandust (telge), siis nt punane on mürgitatud õuna punase põse puhul surma värv. Ometi on Lumivalgukese põsed punased ning silmad mustad, tema surnukeha on värske ja nagu elus. Punane (ja must) osutub elu värviks. Ja lõpus, kui kuninganna end surnuks tantsib, on punane jälle surma värv.

Mürgitamata ounapool on näiliselt elu värvi. Ühes variandis osutub valge värv lõpuks surma värviks, sest lõpuks on kuninganna see, kes sureb.

Kuivõrd Lumivalguke oli surnuna valge nagu lumi ja punane nagu veri ning tema silmad olid mustad (elu), siis ei saanud päkapikud teda musta (surm) mulla sisse matta. Nad panid puhta Lumivalgukese läbipaistvasse klaaskirstu ning kirjutasid sellele kuldsete tähtedega, kes Lumivalguke oli.

Värvikontrastid (opositsioonid) raamivad kogu muinasjuttu. Muinasjutu alguses annab raami must värv. Pimedasse tuppa paistab läbi akna, millel on eebenipuust mustad raamid, maailm, mis on puhas nagu lumi. Punane sümboliseerib muinasjutu alguses vereohvrit - kolm tilka verd!

Kuigi vennad Grimmid seletasid musta, valge ja punase värvi kasutamist universalistlikult sellega, et need on ilusad värvid (vt eespool), ei saa värvide iluga seletada ei nende värvide semantikat, semiootikat ega sümbolismi. Vendade Grimmide "Lumivalgukese” muinasjutu variantide komplitseeritud 
sümbolismiga värvikeele sügavam analüüs nõuab edasist põhjalikumat uurimistööd, mille puhul tuleks lähtuda strukturalistlikust opositsioonide teooriast ning värvide semantikast, sümbolismist ja semiootikast - põhivärvinimede semiootilisest teooriast (Sutrop 2011).

Tuleb analüüsida värvide kasutamist poeetilises tekstis (muinasjutus) ning värvide keelt lingvistilises värviruumis. Kui keskenduda ainult selle muinasjutu kõige olulisematele värvidele - mustale, valgele ja punasele -, siis tuleb tõdeda, et siin on need diskreetsed kategooriad, mille vahel puuduvad üleminekud ja skaalad (vt Odgen 1967: 57-58, 88-89; Chandler 2002: 90-93).

Punane, must ja valge moodustavad kaks ristuvat telge. Akromaatilisel teljel on musta ja valge opositsioon ning selle teljega on risti kromaatiline telg nii, et moodustub kolmnurk, mille tippudeks on põhjal must ja valge ning kõrguses punane (vt Douglas 2000: 206 jj). Analüüs oleks lihtne, kui värvid moodustaksid lihtsaid binaarseid opositsioone (vt Dundes 2002) ega väljendaks samal ajal korraga vastandlikke nähtusi. Tuletan siin meelde, et punane on korraga nii elu kui ka surma värv. Opositsioonis olevad must ja punane võivad aga olla sünonüümid. Näiteks koht, kus laip ei ole veel lagunema hakanud, tüdruk on ikka nagu elus - tema põsed on punased ja silmad on ikka veel mustad.

\section{Tänuavaldus}

Tänan anonüümset retsensenti ja toimetajaid äärmiselt sisukate ja kasulike märkuste, ettepanekute ning viidete eest.

\section{Kommentaarid}

1 Jacob Grimm täiendas hiljem 1808. aasta käsikirja "Schneeweißchen" pealkirja sõnadega "Schneewitchen, auch: das Unglückskind" (vt Ruf 1995: 23). Selle sõna tõlkimisel tuleks jääda vananenud tähenduse - õnnetu laps, õnnetu inimene juurde. Tänapäevased tõlkevasted äpu, hädavares ja ebaõnnestuja on eksitavad. Võimalik oleks tõlkida ka õnnetusehunnik.

2 "Lumivalgukese" muinasjutu värvidega on tegelenud ka näiteks Bruno Bettelheim. Ta käsitleb "Lumivalgukese" muinasjuttu seksuaalses võtmes: "seksuaalne süütus kui valge värv on vastandatud seksuaalsele ihale, mida sümboliseerib punane veri" (2007: 135).

3 Vaatlusalused eestikeelsed tõlked on Lumivalgukeste raamatukeses esitatud järgnevalt: 1810 . a käsikiri lk 9-12, 1812. a esmatrükk lk 14-21 ja 1857. a viimane, 7. trükk lk 22-30.

4 Saksa keeles "so weiß wie der Schnee" (nii valge kui lumi) annab meile deminutiivse nimekuju Sneewittchen e Schneeweißchen (Lumivalguke e Lumivalgeke). 
${ }^{5}$ Erilise kriitika osaliseks said Grimmid julma ema kujutamise eest. Seetõttu asendati juba teisest trükist alates kuri ja jumalakartmatu ema süstemaatiliselt nii "Lumivalgukese" kui ka "Hansukese ja Gretekese" muinasjutus (KHM 15, ATU 327A) kurja ja jumalakartmatu võõrasemaga.

6 Steven Swann Jones peab vastandust muinasjutu alguses esineva punase - kolm punast veretilka - ja muinasjutu lõpu hõõguvpunaste susside vahel juhuslikuks leitmotiiviks (1990: 42).

7 Ma ei hakka siinkohal seda väidet kinnitama ega ümber lükkama. Lisan vaid niipalju, et 1810. aasta käsikirja teises alguses sõidavad krahv ja krahvinna tõllaga mööda kolmest valgest lumehangest. Krahv soovib endale tüdrukut, kes oleks nii valge nagu see lumi. Edasi sõites jõuavad nad kolme verega täidetud auguni ning krahv soovib, et tal oleks tüdruk, kelle põsed oleksid nii punased nagu see veri. Varsti pärast seda lendavad neist üle kolm süsimusta ronka ning krahv soovib jälle tüdrukut, kelle juuksed oleksid nii mustad nagu need rongad. Varsti tuligi selline tüdruk neile vastu. Krahv laskis tal kohe tõlda istuda, aga krahvinna ei vaadanud sellele hea meelega. (vt Lefftz 1927: 125-126; Sutrop 2016: 13).

8 Poliitkorrektses maailmas on Fred Crump afroameeriklaste jaoks "Lumivalgukese" muinasjutu ümber jutustanud nimega "Ebonita and the seven boyz" (Chicago: Urban Ministries, 2008). Nimi Ebonita osutab kangelanna eebenipuukarva nahavärvile.

9 Täpselt sama kordab Jones muutmata kujul ka oma monograafias The new comparative method (1990: 21-23).

\section{Kirjandus}

Aarne, Antti 1910. Verzeichnis der Märchentypen mit Hülffe von Fachgenossen Ausgearbeitet. FF Communiations 3. Helsinki: Suomalainen Tiadeakatemia.

Aarne, Antti \& Thompson, Stith 1961. The types of folktale: a classification and bibliography. Second revision. FF Communications 184. Helsinki: Suomalainen Tiadeakatemia.

Angelopoulos, Anna 2008. Les transformations colorées de Blanche-Neige. Fabula 49 (3-4), lk 203-217 (doi: 10.1515/FABL.2008.017).

Berlin, Brent \& Kay, Paul 1969. Basic color terms: their universality and evolution. Berkley, Los Angeles \& Oxford: University of California Press.

Bettelheim, Bruno 2007. Lumivalgeke. Muinasjuttude võlujõud: muinasjuttude tähtsus ja tähendus. Tartu: Atlex, lk 134-143.

Bolte, Johannes \& Polívka, Georg (toim) 1913. Sneewittchen. Anmerkungen zu den Kinder- u. Hausmärchen der Brüder Grimm. Neu bearbeitet. Bd. 1 (Nr 1-60). Leipzig: Dieterich'sche Verlagsbuchhandlung Theodor Weicher, lk 450-464.

Böklen, Ernst 1910. Sneewittchenstudien. Erster Teil: Fünfundsiebzig Varianten im engern Sinn (Mythologische Bibliothek, III, 2.). Leipzig: J. C. Hinrichs'sche Buchhandlung.

Brüder Grimm 1812-1857a. Kinder- und Hausmärchen. Wikisource (https://de.wikisource. org/wiki/Kinder-_und_Hausmärchen - 17. juuni 2016). 
Brüder Grimm 1812-1857b. Schneewittchen. Wikisource (https://de.wikisource.org/wiki/ Schneewittchen -4 . august 2016).

Brüder Grimm 2010. Schneeweißchen. Derungs, Kurt (toim). Die ursprünglichen Märchen der Brüder Grimm. Die wahren Geschichten neu entdeckt. Grenchen bei Solothurn: Edition Amalie, lk 44-46.

Chandler, Daniel 2007. Semiotics: the basics. 2. tr. London \& New York: Routledge.

Douglas, Graham 2000. Catastrophes in semantic space: signs of universality. Semiotica 132 (2-4), lk 179-280 (doi: 10.1515/semi.2000.132.3-4.179).

Dundes, Alan 2002. Binaarne opositsioon müüdis: pilk Proppi ja Lévi-Straussi väitlusele. Kes on rahvas? Valik esseid folkloristikast. Tartu: Varrak, lk 140-152.

Girardot, N. J. 1977. Initiation and meaning in the tale of Snow White and the seven dwarfs. The Journal of American Folklore 90 (357), lk 274-300 (doi: 10.2307/539520).

Grimm, Jacob 1807. Bedeutung der Blumen und Blätter. Altdeutsche Wälder 1, 131-158. Cassel: bei Thurneissen.

Grimm, Jacob 1846. Vorrede. Giambattista Basile. Der Pentamerone, oder, das Märchen aller Märchen. Saksa keelde tõlkinud Felix Liebrecht. 2 köidet. Breslau, 1. kd, lk XXIIXXIII.

Jones, Steven Swann 1983. The structure of Snow White. Fabula 24 (1-2), lk 56-71 (doi: 10.1515/fabl.1983.24.1-2.56).

Jones, Steven Swann 1990. The new comparative method: structural and symbolic analysis of the allomotifs of "Snow White". FF Communications 247. Helsinki: Suomalainen Tiadeakatemia.

Lefftz, Joseph (toim) 1927. Märchen der Brüder Grimm. Urfassung nach der Originalhandschrift der Abtei Olenberg im Elsaß. Heidelberg: Carl Winters Universitätsbuchhandlung.

Mellen, Philip 1991. Red-white-black: evolution of a motif. Neohelicon. Acta Comparationis Litterarum Universarum 18 (1), lk 179-202 (doi: 10.1007/BF02092527).

Murphy, G. Ronald 2000. Owl, the raven and the dove: the religious meaning of the Grimms' magic fairy tales. New York: Oxford University Press.

Odgen, C[harles] K[ay] 1967. Opposition: a linguistic and psychological analysis. Bloomington: Indiana University Press.

Rölleke, Heinz 2013. Weiß - Rot - Schwarz: "Die drei Farben der Poesie”. Zu Farbspielen in Grimms "Schneewittchen"-Märchen und anderwärts. Fabula 54 (3-4), lk 214-234 (doi: 10.1515/fabula-2013-0019).

Ruf, Theodor 1995. Die Schöne aus dem Glassarg. Schneewittchens märchenhaftes und wirkliches Leben. Würzburg: Königshausen \& Neumann.

Schmidt, Isaac Jacob 1829. Geschichte der Ost-Mongolen und ihres Fürstenhauses, verfasst von Ssanang Ssetsen Chungtaidschi der Ordus; aus dem Mongolischen übersetzt und mit dem Originaltexte, nebst Anmerkungen, Erläuterungen und Citaten aus andern unedirten Originalwerken herausgegeben. St. Petersburg \& Leipzig. 
Shojaei Kawan, Christine 2005-2006. Innovation, persistence and self-correction: the case of Snow White. Estudos de Literatura Oral (E.L.O.) 11-12, lk 237-252.

Sutrop, Urmas 2011. Towards a semiotic theory of basic colour terms and the semiotics of Juri Lotman. Biggam, Carole P. \& Hough, Carole A. \& Kay, Christian J. \& Simmons, David R. (toim). New directions in colour studies. Amsterdam \& Philadelphia: John Benjamins, lk 39-48 (doi: 10.1075/z.167.07sut).

Sutrop, Urmas 2016. Lumivalgukeste raamatuke. Tartu: Eesti Kirjandusmuuseumi Teaduskirjastus.

Toomeos-Orglaan, Kärri 2016. Mis värvi on muinasjutt? Mäetagused 64, lk 35-56 (http:// dx.doi.org/10.7592/MT2016.64.toomeos-orglaan).

Uusküla, Mari \& Sutrop, Urmas 2011. Värvinimede raamat. Töid antropoloogilise ja etnolingvistika vallast 5. Tallinn: Eesti Keele Sihtasutus.

Vaz da Silva, Francisco 2007. Red as blood, white as snow, black as crow: chromatic symbolism of womanhood in fairy tales. Marvels \& Tales: Journal of Fairy-Tale Studies 21 (2), lk 240-252 (http://digitalcommons.wayne.edu/marvels/vol21/iss2/4 - 3. august 2016).

\section{Summary}

\section{Colour names and colours in the versions of the Snow White fairy tale by the Brothers Grimm}

\section{Urmas Sutrop}

Keywords: oppositions, primary colour names, Snow White, structuralism, the Brothers Grimm

The article discusses three versions of the Snow White fairy tale by the Brothers Grimm (1810, 1812, and 1857), delving into the meanings of colours and colour names occurring in them as well as changes in the names and meanings. The analysis proceeds from the structural method of fairy tale study and explores the symbolic meaning oppositions of colours and their names, such as in/out, light/dark, life/death, logical/mythological. The analysis is also based on the differentiation drawing on the theory of primary colours, according to which black, white, and red are the most fundamental colour names. However, the use of colour names (semantics and symbolism) is complicated in the versions of the Snow White fairy tale, as a colour may have several oppositional meanings. It is not just simple binary oppositions. The Brothers Grimm regarded the colours black, white, and red as beautiful. Jacob Grimm depicted them as the three colours of poetry. 